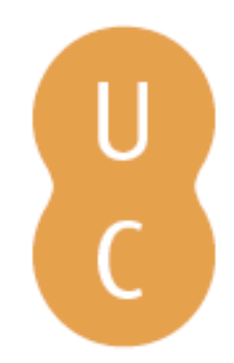

\title{
pommalina
}

\section{Jueces, premios y castigos en el Más Allá de Plutarco}

Autor(es): $\quad$ San Cristóbal, Ana Isabel Jiménez

Publicado por: Imprensa da Universidade de Coimbra

URL

persistente:

URI:http://hdl.handle.net/10316.2/32886

DOI:

DOI:http://dx.doi.org/10.14195/978-989-721-012-9_17

Accessed : $\quad$ 26-Apr-2023 13:18:42

A navegação consulta e descarregamento dos títulos inseridos nas Bibliotecas Digitais UC Digitalis, UC Pombalina e UC Impactum, pressupõem a aceitação plena e sem reservas dos Termos e Condições de Uso destas Bibliotecas Digitais, disponíveis em https://digitalis.uc.pt/pt-pt/termos.

Conforme exposto nos referidos Termos e Condições de Uso, o descarregamento de títulos de acesso restrito requer uma licença válida de autorização devendo o utilizador aceder ao(s) documento(s) a partir de um endereço de IP da instituição detentora da supramencionada licença.

Ao utilizador é apenas permitido o descarregamento para uso pessoal, pelo que o emprego do(s) título(s) descarregado(s) para outro fim, designadamente comercial, carece de autorização do respetivo autor ou editor da obra.

Na medida em que todas as obras da UC Digitalis se encontram protegidas pelo Código do Direito de Autor e Direitos Conexos e demais legislação aplicável, toda a cópia, parcial ou total, deste documento, nos casos em que é legalmente admitida, deverá conter ou fazer-se acompanhar por este aviso. 


\section{Nomos, Kosmos \& Dike in Plutarch}

José Ribeiro Ferreira, Delfim F. Leão \& Carlos A. Martins de Jesus (eds.) 


\title{
Jueces, premios y castigos en el Más Allá de Plutarco ${ }^{1}$
}

\author{
Ana Isabel Jiménez San Cristóbal \\ Universidad Complutense de Madrid
}

\begin{abstract}
Plutarch mentions in his writings the existence of three judges, Minos, Rhadamanthys, and Aeacus. They judge people in Hades and decide whether they must be condemned in Tartarus or can live happily on the Isles of the Blessed. Rewards and punishments depend on the moral behaviour of the souls during their lives. The aim of my work is to analyze the background against which Plutarch elaborates his idea of justice in the Netherworld. He suits and reworks traditional motifs but also leaves a personal mark on his netherworldly imagery.
\end{abstract}

\section{La existencia post mortem}

Plutarco aborda en diversas obras la cuestión de la inmortalidad del alma y las posibles formas de existencia post mortem ${ }^{2}$. En el Escrito de consolación a Apolonio trata de confortar a su amigo por la pérdida de su hijo recurriendo a un relato atribuido a "los antiguos poetas y filósofos" (120B), según el cual, los muertos que han sido piadosos disfrutarán de cierto honor y privilegio y sus almas habitarán un lugar apartado. Plutarco cita entonces unos versos de Píndaro (120C-E, cit. Pi. fr. 129 Maehler [= 58 Cannatà Fera], portavoz de los poetas, para ilustrar las delicias de ese lugar. A continuación, en representación de los filósofos, reproduce literalmente un extenso pasaje del Gorgias platónico en que se expone cómo la conducta de los hombres en vida condiciona el destino de las almas tras la muerte (120E-121D, cf. Pl. Grg. 523a-524a).

Para desarrollar su concepto de vida tras la muerte Plutarco se inspira efectivamente en la escatología platónica ${ }^{3}$, pero dispone además de un amplio

${ }^{1}$ Este trabajo forma parte del Proyecto de Investigación "Cosmogonía y escatología en la antigua Grecia. Influjos y paralelos con el Próximo Oriente”, financiado por el MEC (FFI 201017047). Agradezco a Rosa Aguilar, A. Bernabé, F. Frazier y A. Pérez Jiménez sus sugerencias, indicaciones bibliográficas y correcciones.

${ }^{2}$ Aquí nos centraremos en Plu. Cons. ad Apoll.120E-121D, De sera num. vind. 563B-568A, De gen. Socr. 589F-592E, De fac. lun. 940F-945D; fr. 178 Sandbach; Comp. Cimon. et Luc. 1.2. Véanse además: Plu. Cons. ad Apoll.107D-110E, De sera num. vind. 560A-F; Cons. ad ux. 611D y ss.; De fac. lun. 942D, Non posse suav. 1104A-1107A; Rom. 28; fr. 177 Sandbach. Sobre este particular, véanse R. Aguilar 1981; I. P. Culianu 1983: 43-47; F. E. Brenk 1986: 2117-2130; F. E. Brenk 1987: 275-294; A. Pérez Jiménez 1993: 108-114; F. E. Brenk 1994; J. Boulogne 1994; G. Roskam 1999: 468-474; J. Boulogne 2008; F. Frazier 2010.

${ }^{3}$ Para la influencia platónica, véase R. M. Jones 1916: 48-56, 58-60, 69ss; W. Hamilton 1934; W. Hamilton 1934a; G. Soury 1942: 7, 73-82, 177-210; Y. Vernière 1977: 95101, 119-121, 124-129; R. Aguilar 1981: 13-22; F. E. Brenk 1987: 262-275; P. Donini 
repertorio de catábasis y viajes celestes que abordan la existencia ultramundana desde una perspectiva literaria, filosófica y religiosa ${ }^{4}$. El propósito de este trabajo es pasar revista a los antecedentes sobre los que Plutarco elabora su concepto de justicia en el Más Allá, adaptando y reelaborando relatos y motivos tradicionales, pero sin renunciar a sus propias convicciones e ideas y dejando su impronta personal en la manufactura de la imaginería ultramundana.

\section{Los jueces del Hades}

En el pasaje del Gorgias citado por Plutarco (Cons. ad Apoll.121C-121D, cf. P1. Grg. 523e-524a [Orph. Fr. 460]) se menciona la presencia en el Hades de tres jueces, Minos, Éaco y Radamantis, nombrados por Zeus. Son los encargados de juzgar a los hombres y decidir si han de ser condenados en el Tártaro o habitar felices en la Isla de los Bienaventurados ${ }^{5}$, según haya sido su conducta moral. Radamantis juzga a los de Asia, Éaco, a los de Europa y Minos dicta sentencia definitiva en caso de duda. Plutarco destaca en varios de sus escritos las virtudes éticas que los tres tuvieron en vida y que les capacitan para ejercer como jueces en el Hades ${ }^{6}$. Éaco sobresalió como buen padre y sobre todo fue piadoso hasta el extremo de recibir culto tras su muerte (Plu. Par. min. 311E, 312B; Thes. 10.3; Dem. 28.4, 5). Radamantis descolló como juez y guardián de las normas fijadas por su hermano Minos (Thes. 16.4, cf. Od.19.179), de quien, a su vez, se elogia su condición de rey, legislador y especialmente discípulo de Zeus (e.g. Max. cum. princ. 776E, De sera num. vind. 550B) ${ }^{7}$.

La elección por parte de Plutarco del pasaje del Gorgias no parece casual ${ }^{8}$. Los jueces infernales no están atestiguados en la literatura griega de los siglos V-III a. C., salvo en una breve mención de Píndaro (O. 2.58-60 [Orph. Fr. 445]) y en varios pasajes platónicos ( $R$. 614b [OF 461], Grg. 523e-524a [Orph. $F r .460])^{9}$. Píndaro hace una vaga referencia al juicio de las almas, menciona a

1988: 128-129, 142-143; A. Pérez Jiménez 1993: 113, n. 31; F. E. Brenk 1994: 9-21; M. A. Durán López 1994; J. Boulogne 1999; A. Pérez Jiménez 2001: 201-203; F. Frazier 2010. Sobre los premios y castigos en la escatología platónica, cf. A. BERnABÉ 2011: 155188.

${ }^{4}$ Véanse especialmente Y. Vernière 1977: 153-194, 284-294; A. BernabÉ 1996, 78-79; M. A. Santamaría Álvarez 2007.

${ }^{5}$ Sobre la presencia de este concepto en Platón y Plutarco, véase M. Martínez 1999: 98-106.

${ }^{6} \mathrm{La}$ función legisladora de Minos y Radamantis ha sido estudiada por K. J. HöLKeskamp 1999: 44-59; sobre su presencia y papel en el Hades, véase C. Sourvinou-Inwood 1999: 32-34, 54-55, 87-88; E. Coelho 2007.

${ }^{7}$ Otras menciones relativas a las actuaciones, crueldad y benevolencia de Minos pueden verse en Thes. 15.1, 19.5-10, 25.3; Aet. Rom. et Gr. 299A; De tuend. san.132E.

${ }^{8}$ Las causas han sido bien estudiadas por M. A. Durán López 1994, quien muestra cómo Plutarco utiliza un mito protréptico como elemento consolatorio.

${ }^{9}$ En la Apología de Sócrates (Apol. 41a, Orph. Fr. 1076 I), se menciona a Minos, Radamantis y Éaco, pero no se especifica si juzgan las almas de los muertos, o simplemente dirimen pleitos 
los jueces, pero no los nombra y, sobre todo, centra su atención en las almas de los no piadosos ${ }^{10}$, cuestión que se aleja notablemente del propósito de Plutarco. Por su parte, Platón en el mito de Er narrado en la República (614cd) menciona la presencia de jueces infernales, pero sin ahondar demasiado en sus atribuciones y sin dar sus nombres ${ }^{11}$. En qué consiste el juicio de las almas lo detalla un pasaje del Axioco $(371 c)^{12}$, un diálogo cuya autencidad es cuestionada $^{13}$, pero que en cualquier caso presenta una visión escatológica inspirada en descripciones del Más Allá platónico. En el Axíoco sí se nombran los jueces, pero no se distinguen sus funciones. Cabe pensar que Plutarco ha elegido el pasaje del Gorgias por ser uno de los más detallados que conoce y por la innovación que representa el sistema de juicios allí descrito. Según Platón, el procedimiento actual deriva del propio Zeus y trata de solventar el sistema vigente en tiempos de Crono, cuando el juicio se realizaba el mismo día en que moría la persona a quien se juzgaba y los jueces eran también hombres vivos. Zeus nombra ahora a sus propios hijos, que son mortales, y a diferencia de los jueces terrenales, los infernales juzgan desnudos, desprovistos de intereses materiales e inmunes a todo tipo de corrupción ${ }^{14}$. Del mismo modo deben estar desnudas y desprovistas de riqueza las almas a quienes se juzga para garantizar la objetividad de los jueces (Grg. 523 b-e, apud Plu. Cons. ad Apoll.121A-C) $)^{15}$.

Por otra parte, hemos visto que Plutarco atribuye este ideario a un "relato de antiguos poetas y filósofos”, entre los que se encuentran Píndaro y Platón, pero el recurso a esta fórmula tradicional puede implicar otras fuentes. Platón emplea expresiones semejantes para referirse a doctrinas atribuidas a Orfeo y Museo, que el filósofo adapta y transforma sabiamente hasta hacerlas suyas ${ }^{16}$. En los testimonios órficos más antiguos no se menciona el juicio en el Más Allá ${ }^{17}$, pero en su tránsito ultramundano el iniciado ha de superar una serie de

entre ellos, función que tiene ya Minos en Homero (Od. 11.568-571), cf. C. SourvinouInwOod 1999: 87-88; A. BERNABÉ 2011: 159-163.

${ }^{10}$ M. A. Santamaría Álvarez 2003: 265-271.

${ }^{11}$ Sobre el mito de $\operatorname{Er}(\mathrm{Pl}$. R. 614b-621b) y la escatología de la República, cf. especialmente H. Richardson 1926 y A. Bernabé 2011: 172-178 con bibliografía.

${ }^{12}$ Cf. Y. Vernitère 1977: 291-292. Sobre la escatología de este diálogo, véase A. Bernabé 2011: 178-188, con bibliografía. Platón menciona también el juicio de las almas en la Carta Séptima (P1. Ep. 7, 335a; Orph. Fr. 433 I) y en las Leyes (P1. Lg. 959b), pero sin detallar en qué consiste.

${ }^{13}$ Cf. el estado de cuestión de P. Gómez Cardó 1992.

${ }^{14}$ Sobre el mito del Gorgias, véanse E. R. Dodds 1959: 372-379; L. Bescond 1986; J. Dalfen 2002: 223-225; D. Sedley 2009; A. Bernabé 2011: 157-163.

${ }^{15}$ Cf. M. A. Durán López 1994: 647. Sobre la idea de la desnudez de las almas en Plutarco, cf. G. Soury 1942: 215-216.

${ }^{16}$ Cf. A. Bernabé 1998: 39-57, 91-93; A. Bernabé; A. I. Jiménez San Cristóbal 2008: 53-55; A. Bernabé 2011: 7-15.

${ }^{17}$ Pero se trata de una creencia asociada al orfismo y pitagorismo desde antiguo. Platón (Ep. 7, 335a, [Orph. Fr. 433 I]) menciona ciertos escritos antiguos y sagrados, probablemente atribuidos a Orfeo y Museo, que ilustran sobre el juicio post mortem. Con Pitágoras y su secta lo 
pruebas, como beber de la fuente apropiada o no equivocarse de camino, y debe demostrar además a unos guardianes, a Perséfone y a otras divinidades infernales que ha cumplido con sus obligaciones rituales y merece, en consecuencia, un destino dichoso ${ }^{18}$. Plutarco, por su condición de homo religiosus, conoce bien estas doctrinas y su literatura y es consciente de que la escatología platónica es deudora en ocasiones de la órfica ${ }^{19}$. Así, en el Gorgias la idea de los dos caminos recuerda la encrucijada con dos fuentes, a la derecha y a la izquierda, que aparecen descritas en las laminillas órficas desde finales del s. V a. C. ${ }^{20}$ Plutarco sigue la doctrina platónica, como él mismo indica con el vocablo 'filósofos', pero con el recurso a la fórmula tradicional de los 'antiguos poetas' parece sugerir que el propio Platón debe mucho a su vez a otras doctrinas. En el fondo, lo que hace Plutarco es apoyar el prestigio de la cita platónica con el prestigio de la poesía antigua y revelada.

El pasaje de la Consolatio es el único en que Plutarco cita juntos a los tres jueces del Hades, si bien otras veces se refiere a ellos de forma individual. En la biografía de Catón el Mayor (23.2) hay una alusión implícita al juicio de las almas que encabeza Minos. El texto es poco relevante, pero muestra una visión escatológica en que cada cual retoma la función que tenía durante su existencia terrenal: Minos fue juez en vida y lo sigue siendo en el Hades; del mismo modo, Isócrates y sus discípulos, oradores y logógrafos, ejercerán como tales a su muerte. En otro pasaje (fr. 201.6 Sandbach) Plutarco recurre a Homero para mostrar que Radamantis habita la llanura Elisia y los confines de la tierra donde moran los enviados por los dioses ${ }^{21}$. En principio, la mención de Radamantis es puramente poética, por su relación con la Elisea ${ }^{22}$, y no se habla del juicio de las almas, sino más bien del lugar reservado a quienes han vivido piadosamente. El propio Plutarco añade en su comentario que la llanura Elisia es el nombre que se da a la superficie de la luna. Sabemos por el mito de Sila narrado en el Sobre la cara que aparece en el orbe de la luna (942D) que para Plutarco la luna se identifica con la morada de Perséfone y es el lugar al que llegan los espíritus nobles tras una primera muerte y en el que se disuelven tras la desunión de alma e intelecto que supone la segunda muerte ${ }^{23}$.

En el Sobre la imposibilidad de vivir placenteramente según Epicuro

relacionan Arist. EN 1132b 21ss. y Iamb. VP 86, 155, 179; DK 58c 3, ap. D. L. 8.35, cf. M. A. Santamaría Álvarez 2003: 268.

${ }^{18}$ Cf. A. Bernabé; A. I. Jiménez San Cristóbal 2008: 171-174.

${ }^{19}$ Y. Vernière 1977: 154-157; A. Bernabé 1996.

${ }^{20}$ Orph. Fr. 474-484a, cf. A. Bernabé; A. I. Jiménez SAn Cristóbal 2008: $19-52$.

${ }^{21}$ Cf. Od. 4.563, pasaje que se cita también en De fac. lun. 942F, 944C.

${ }^{22}$ Cf. C. Sourvinou-Inwood 1999: 32-34.

${ }^{23}$ Sobre la segunda muerte, véase infra, n. 50 . 
(1104A-1107A), Plutarco ataque la doctrina epicúrea sobre la muerte y aboga por la concepción platónica de que la conducta moral en vida determina la existencia ultraterrena ${ }^{24}$. El miedo a los juicios y castigos del Hades, dice Plutarco, contiene en cierta medida a los que son injustos y malvados. En cambio, prosigue más adelante $(1104 \mathrm{~B}, 1104 \mathrm{D})$, poco efecto tiene la figura de Éaco para la mayoría descreída, que no cree en los terrores del Hades.

El veredicto de Minos, Radamantis y Éaco determina si las almas han de tomar el camino que lleva a la Isla de los Bienaventurados, donde gozarán de premios o, por el contrario, el que conduce al Tártaro en que yacerán sometidas a suplicios. A estos caminos se suman el de la reencarnación, que significa una vuelta al mundo actual, y el camino que conduce al mundo superior, al que se llega por el trance de la segunda muerte expuesta en el De facie ${ }^{25}$. Aquí vamos a centrarnos en los premios y castigos que aguardan al alma en el Hades, sin abordar los aspectos de la reencarnación o las consecuencias de la segunda muerte. Al igual que Platón, Plutarco recurre al mito para exponer las retribuciones y suplicios del alma en tres de sus diálogos. En el De la tardanza de la divinidad en castigar, introduce el mito de Tespesio; en el De facie, el de Sila, y en el Sobre el demón de Sócrates, el de Timarco ${ }^{26}$.

\section{Divindades vengadoras y castigos en el Más Allá}

La suerte de las almas condenadas se expone principalmente en el De Sera (563B-568A) al hilo del mito de Tespesio ${ }^{27}$. En su experiencia ultramundana, inspirada sobre todo en el mito de Er platónico y localizada en el cielo ${ }^{28}$, Tespesio contempla distintos tipos de almas: unas puras y brillantes que

${ }^{24}$ Cf. H. Adam 1974: 67-70; F. Albini 1993: 24ss; G. Roskam 1998: 470-472.

${ }^{25}$ Sobre los caminos en la escatología de Plutarco, véase M. A. Durán López 2001.

${ }^{26}$ Estudios de conjunto de los tres mitos pueden verse en G. Soury 1942; F. E. Brenk 1977; Y. Vernière 1977; R. Aguilar 1981; F. E. Brenk 1994; R. Aguilar 1996a. La bibliografía más relevante de cada uno está citada en las notas 27, 37 y 49.

${ }_{27}$ Sobre este mito, véanse G. Soury 1942: 211-227; J. Hani 1975: 111-115; Y. Vernière 1977: 108-112, 201-203; R. Aguilar 1981: 1-26; Y. Vernière 1986: 340-352; R. Aguilar 1993: 20-23; M. A. Durán López 1999; H. G. Ingen kamp 2001: 134; A. Pérez Jiménez 2001; I. Gallo 2003-2004: 202-204; M. A. Santamaría Álvarez 2007; F. Frazier 2010; M. TAufER 2010.

${ }^{28}$ Sobre la inspiración platónica, véanse Y. Vernière 1977: 288; F. E. Brenk 1977: 136139; M. A. Durán López 1999: 215-217; M. Taufer 1999; J. Sirinelli 2000: 406-410; C. Wiener 2004; F. Frazier 2010. Y. Vernière 1977: 285-293 y M. A. Santamaría Álvarez 2007: 879-886 señalan paralelismos y motivos coincidentes entre la aventura de Tespesio y las nekyiai de la Odisea (Od. 11 y 24) y la del cínico Menipo (D. L. 6.101), la catábasis de Dioniso en las Ranas de Aristófanes, los relatos de viaje al Hades atribuidos a Heráclides Póntico y Clearco de Solos, e incluso la catábasis de Eneas (Verg. Aen. 6). Sobre los ecos dionisíacos en la descripción de Tespesio, véanse Y. Vernière 1964; Y. Vernière 1986: 351; F. E. Brenk 1987: 287-288 y M. A. Durán López 1999: 211-214, 218-219; para los motivos de inspiración órfica, cf. A. Bernabé 1996: 78-79; M. A. Santamaría Álvarez 2007: 879-881. 
ascienden derechas, y que deben ser las almas justas, y otras, probablemente las condenadas, marcadas por manchas o llagas, que giran en círculo inclinándose hacia arriba y hacia abajo y lanzando gritos inarticulados (564A-E). Las almas injustas han de rendir cuentas ante unas divinidades vengadoras y someterse a castigos para purificarse de las faltas cometidas en vida que probablemente atentaban contra la ética o la justicia vigentes $(564 \mathrm{E}-565 \mathrm{~B})^{29}$.

Adrastea, hija de Ananke y Zeus, es la vengadora suprema de todas las injusticias. Le auxilian en su labor, Poine, Dike y Erinis. La primera se ocupa de quienes han sido castigados en vida con penas que sólo atañen al cuerpo pero no corrigen al alma. Dike recibe a quienes no fueron castigados ni purificados en vida por delitos de gran envergadura, hace visibles sus culpas a todos y les obliga a purificarse liberándose de sus pasiones con dolores y sufrimientos intensos. A medida que se van purificando las almas van desapareciendo las manchas, llagas y cicatrices, secuela de sus pasiones ${ }^{30}$. Algunas almas, sin embargo, no logran purificarse y se ven abocadas a un nuevo nacimiento. Por último, Erinis, la colaboradora más severa de Adrastea, persigue a quienes son absolutamente incurables y los aprisiona en un lugar indecible e invisible. Plutarco retoma una serie de divinidades que vengan los crímenes de sangre, bien atestiguadas desde época clásica, especialmente en los trágicos ${ }^{31}$. La novedad principal es que las presenta como un conjunto, a cuya cabeza está Adrastea, y delimita su esfera de actuación al mundo de los muertos ${ }^{32}$. La clasificación de las almas del $D e$ Sera guarda importantes reminiscencias del Fedón platónico $(113 \mathrm{~d}-114 \mathrm{~b})^{33}$, en que se distingue entre quienes han vivido moderadamente y han de purificarse hasta que son absueltos, aquellos que son irremediables y se ven arrojados para siempre al Tártaro por la magnitud de sus crímenes, quienes han cometido delitos graves pero curables y, finamente, quienes vivieron de forma piadosa $y$ habitarán una morada pura.

Tespesio avanza en su camino y ve la sima de Lete, una gruta similar a los antros báquicos, por la que Dioniso condujo arriba a Sémele, y en la que las almas se humedecen y emborrachan para olvidar antes de reencarnarse

${ }^{29}$ Véase F. Frazier 2010: 155-156.

${ }^{30}$ Sobre el simbolismo de los colores asociados a los diferentes tipos de almas, cf. G. Soury 1942: 217-220; Y. Vernière 1977: 147; I. P. Culianu 1983: 46-47; J. Boulogne 1994: $223-$ 224, 227-229, 233 y n. 97; F. Frazier 2010: 154-155.

${ }^{31}$ Poine y Dike aparecen en A. Ch. 947; Dike y Erinis, en A. Eu. 510, Ag. 1432; S. Ai.1390, Tr. 808; E. Med. 1389; PDerveni col. IV 9; y Dike es invocada en S. Ant. 451. Por su parte, Adrastea castiga la soberbia en A. Pr. 936 y P1. R. 451a.

32 Sobre su función, véanse G. Soury 1942: 214-215; Y. Vernière 1977: 234-241; R. Aguilar 1986: 6-7 y n. 10; R. Aguilar 1996: 159 y n. 132; R. Aguilar 1996a: 286-288.

${ }^{33}$ Cf. F. Frazier 2007: 195-196; F. Frazier 2010: 152-153. Sobre la escatología del Fedón, cf. A. Bernabé 2011: 163-172. Categorías similares de condenados pueden verse en P1. Grg. $525 \mathrm{c}, 526 \mathrm{~b}$, R. 615a-b. 
(566A-B) $)^{34}$.Tespesio pasa también por la sima de los tres démones y el oráculo ${ }^{35}$ antes de volver al lugar los castigos (566E-567D). Contempla los suplicios de cuantos vivieron disimulando su maldad y con fama de virtuosos en vida. E1 espectáculo de tormentos es ahora más atroz y duro si cabe. Los condenados han de sacar fuera el interior del alma y se contorsionan y retuercen de forma anormal. Para purificar las almas unos démones las sumergen sucesivamente en tres lagunas cercanas, una de oro hirviendo, otra helada de plomo y la última áspera y dura de hierro $(567 \mathrm{C}-\mathrm{D})$. Las almas allí sumergidas van cambiando de color, aspecto y consistencia hasta que recobran su luminosidad original (565C). A continuación, las que van a reencarnarse en animales son golpeadas por artesanos que las adaptan a sus nuevas formas $(567 \mathrm{~F})$. Los procedimientos empleados para regenerar las almas recuerdan a los que usa la alquimia para transformar los metales viles en nobles. La imagen, ausente en la escatología platónica, tal vez se inspire en escritos gnósticos que describen la creación del alma del mundo como una mezcla de tipo alquímico ${ }^{36}$.

Encontramos nuevas referencias a los castigos en el mito de Timarco, narrado en el De genio $(589 \mathrm{~F}-592 \mathrm{E})^{37}$, si bien Plutarco se interesa aquí más por presentar una doctrina sobre la naturaleza del alma que por los aspectos escatológicos. El protagonista contempla una sima de la que escapan aullidos, llantos y gemidos innumerables de personas y animales. El lugar ha sido interpretado, no sin controversia, como el mundo inferior en que residen las almas que van a reencarnarse $(590 \mathrm{~F})^{38}$. Un poco más adelante se habla del Hades como lugar de castigo que arrebata las almas mancilladas e impuras que deben nacer de nuevo (591C) $)^{39}$. En cambio, las almas que ya han cumplido su ciclo de nacimientos son acogidas por la luna. Sus concavidades son lugar de purificación y castigo de las culpas y puertas por las que las almas circulan de la luna al cielo o bien hacia la tierra. El propio movimiento de las almas revela cuál es su condición: se mueven de forma recta y ordenada las almas

${ }^{34}$ Cf. G. Soury 1942: 217 y n. 1; Y. Vernière 1964; Y. Vernière 1977: 185-188, 221; R. Aguilar 1981: 7-11; Y. Vernière 1986: 351; F. E. Brenk 1987: 287-288; A. Pérez Jiménez 1993: 114; R. Aguilar 1996a: 288-289; M. A. Durán López 1999; A. Pérez Jiménez 2001: 204-206; R. Aguilar 2010: 9-10.

35 Y. Vernière 1977: 188-190; R. Aguilar 1981: 11; R. Aguilar 1996a: 289-290; M. A. Durán López 1999: 214-215; A. Pérez Jiménez 2001: 206-208.

${ }^{36}$ Cf. J. Boulogne 1994: 218, 227-234; J. Boulogne 2008: 60-61. Agradezco a A. Pérez Jiménez la sugerencia de la posible relación con la alquimia, así como las referencias bibliográficas.

37 Sobre el mito, cf. W. Hamilton 1934a; G. Soury 1942: 153-175; G. MÉautis 1950; Y. Vernière 1977: 105-108; J. Hani 1975; R. Aguilar 1981: 27-44; Y. Vernière 1986: 340-352; R. Aguilar 1993: 23-24; R. Aguilar 1996a: 292-293; I. Gallo 2003-2004: 200-202.

${ }^{38}$ Como el Tártaro lo ven F. Cumont 1966: 136, n. 3; Y. Vernière 1977: 182-183. Con la tierra lo identifican R. M. Jones 1916: 57; G. MÉautis 1950: 208; véase R. Aguilar 1981: 35 y R. Aguilar 2010: 7-8, con bibliografía.

${ }^{39}$ Cf. R. Aguilar 1981: 36. 
que por crianza y educación tienen una parte irracional no demasiado dura ni obstinada, mientras que se inclinan hacia arriba y hacia abajo las que tienen un carácter indómito (592A). Son evidentes los ecos del Fedro platónico (247b) en que la situación de las almas está ligada a su capacidad de controlar las pasiones en vida ${ }^{40}$.

En esa dicotomía entre lo racional y lo irracional incide también el $D e$ facie. Aquí todas las almas, racionales y pasionales, al morir están abocadas a errar durante cierto tiempo entre la tierra y la luna, pero su condición no es la misma ya que las injustas y disolutas pagan por sus ofensas, mientras que las buenas se purifican del miasma del cuerpo en un lugar llamado pradera del Hades del que luego partirán hacia la luna $(943 C)^{41}$. Desafortunadamente Plutarco no explicita cómo pagan las almas injustas esas ofensas. En todo caso, lo que determina una vez más la situación del alma es la capacidad de raciocinio que le ayuda a vencer las pasiones.

Hallamos también referencias a los castigos en un fragmento del tratado Sobre el alma (fr. 178 Sandbach) ${ }^{42}$. Al hilo de la comparación entre lo que experimentan los iniciados en el ritual y en el momento de morir ${ }^{43}$, Plutarco describe el panorama que acoge al alma a su muerte. El fiel tiene visiones sagradas y experimenta efectos físicos típicos del terror y la angustia provocados tal vez por la incertidumbre o, mejor, porque el alma contempla allí los "terrores del Hades" ${ }^{4}$. El panorama de los profanos resulta desolador: una multitud impura que se hunde en el barro, pisoteándose y empujándose unos a otros. En este ejemplo la idea de justicia está ligada al ideario religioso y a la práctica cultual: quienes se inician y participan en los misterios disfrutarán en el Hades de una existencia privilegiada, frente a los profanos que yacerán en el fango. No es relevante determinar si Plutarco se está refiriendo a los misterios de Eleusis, a los órficos o a los de Isis ${ }^{45}$, porque probablemente el imaginario es compartido por los misterios en general. Lo importante es que testimonia la supervivencia de una concepción de la justicia ligada a la iniciación y al cumplimiento de ritos, propia de cultos mistéricos como el orfismo, y de la que ya Platón ( $R$. 363cd, 364b, 364e, 366a; Phd. 69c, Grg. 493a-c) se hacía eco siglos atrás fundamentalmente para denunciarla ${ }^{46}$.

${ }^{40}$ Cf. R. Aguilar 1981: 40-41.

${ }^{41}$ Cf. G. Soury 1942: 185-186; Y. Vernière 1977: 190; A. Pérez Jiménez 2011.

${ }^{42}$ Cf. G. Soury 1942: 186-188; R. Aguilar 1981: 91-94; Y. Vernière 1986: 349-350; A. BERnABÉ 2001.

${ }^{43}$ Sobre el particular véanse Y. Vernière 1977: 196-197; F. Díez de Velasco 1997: 413422; A. Bernabé 2001: 10-21.

${ }^{44}$ Véase también PDerveni col. V 5ss; cf. A. Bernabé 2002.

${ }^{45}$ Véase A. Bernabé 2001: 11-12, con bibliografía sobre la discusión.

${ }^{46}$ Otros tormentos pueden verse en $\mathrm{P} 1$. Axioc. 371d. Sobre la concepción religiosa de la justicia, cf. H. G. Ingen kamp 2001; A. I. Jiménez San Cristóbal 2005; A. Bernabé 2011: 188-204. 
El análisis de los textos analizados muestra que las almas son condenadas por un comportamiento en vida que atenta contra la ética o la justicia (en el De sera), por su incapacidad para controlar las pasiones (en el De genio y en el De facie) o por causas estrictamente religiosas, a saber el hecho de no estar iniciado. Todos estos motivos se encuentran ya en la escatología platónica y en la de los cultos mistéricos, de los que Plutarco es, por tanto, deudor ${ }^{47}$. Si comparamos los castigos que Platón augura a los condenados con los de los escritos plutarqueos, observamos similitudes, pero también notables diferencias. En el Fedón y en la República los condenados yacen en el barro, el mismo castigo que cita Plutarco en el De anima ${ }^{48}$. En el Gorgias (493b) Platón describe que los insensatos y no iniciados son castigados a llevar agua en un cedazo a una tinaja agujereada, un castigo que Plutarco no menciona, pese a citar pasajes textuales del Gorgias en la Consolatio. Por último, en el Axioco (371d) los condenados son lamidos por fieras salvajes o quemados por las divinidades vengadoras, castigo comparable a las manchas o llagas que estigmatizan las almas condenadas en Plutarco. Da la impresión de que el de Queronea se aleja en ciertos aspectos del filósofo ateniense. Mientras en los escritos de Platón el alma se ve obligada a realizar actividades penosas, en los de Plutarco tiene una actitud más pasiva y sufre los tormentos "en carne propia”. Así es sumergida en lagunas, golpeada por artesanos y constreñida a moverse en círculo o retorcerse. En general, Plutarco prescinde de las detalladas descripciones platónicas de los terrores del Hades y opta por una imagen más abstracta y aséptica del castigo. Habla de sufrimientos intensos, gemidos o lamentos, pero rara vez explicita su causa o procedencia y evita en gran medida el lado cruel y violento. Parece que Plutarco prefiere no incidir demasiado en ciertos aspectos, bien porque los considera de sobra conocidos, bien porque piensa que los castigos son más simbólicos que reales.

\section{Los premios en el Hades}

Los premios que aguardan las almas de los buenos se exponen fundamentalmente en el De facie, en la narracción del mito de Sila $(940 \mathrm{~F}-945 \mathrm{D})^{49}$. Leemos allí que ningún individuo mezquino o impuro puede

${ }^{47}$ En el Fedón (69d), Platón dice que los iniciados son los filósofos y se desmarca de una visión "ritualista". En cambio, Plutarco, de acuerdo con lo que leemos en Cons. ux. 611D, valora las iniciaciones y participa activamente junto con su mujer en el culto, cf. Y. VERNière 1977: 220-225; Y. VERNIÈRE 1986: 336-339. Sobre la transposición de la imaginería tradicional, cf. Y. VERNIÈRE 1977: 178-194.

${ }^{48}$ Pl. Phd. 69c, R. 363c-d; véanse también Pl. Phd.113d-114b, R. 615a.

49 Sobre el mito, cf. W. Hamilton 1934; G. Soury 1942: 176-210; Y. Vernière 1977: 102-105; R. Aguilar 1981: 45-64; Y. Vernière 1986: 346-352; P. Donini 1988; A. Pérez 
subir al extremo límite de la tierra, el lugar donde los nobles llevan una vida apacible hasta la segunda muerte $(942 \mathrm{~F})^{50}$. Más adelante dice que las almas nobles pasan un tiempo en la zona más suave del aire a la que se denomina "las praderas del Hades" para librarlas de las impurezas del cuerpo (943C-D) ${ }^{51}$. Algunas de ellas no consiguen superar esa fase intermedia y son rechazadas. Otras, en cambio, logran llegar a la luna y son tocadas como vencedoras con coronas de plumas que se llaman coronas de la rectitud porque esas almas lograron someter y adiestrar su parte irracional en vida. El premio supremo

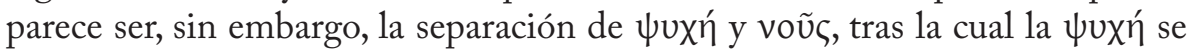
disuelve en la luna y el voũ alcanza el sol $(944 \mathrm{E})^{52}$.

La idea de la estancia feliz en la pradera, probablemente de raigambre indoeuropa, es frecuente en la escatología griega desde Homero y tiene gran fuerza en los órficos y, por supuesto, en Platón ${ }^{53}$. En cuanto a la corona tenemos ejemplos desde Píndaro en que las almas de los bienaventurados se adornan con coronas en el Más Allá como símbolo de victoria sobre la muerte ${ }^{54}$. Plutarco menciona también la pradera y corona en relación con la suerte de las almas bienaventuradas en el fr. 178 Sandbach, al que ya nos hemos referido a propósito de los castigos. Leemos allí que el iniciado disfruta de un destino feliz entre hombres purificados de su misma condición. El rasgo que define esa condición es haber participado en los misterios. Una luz asombrosa, lugares puros y praderas acogen al iniciado que llega purificado y coronado. La corona, además de simbolizar el triunfo sobre la muerte, le sirve al difunto de seña de identidad que lo identifica como iniciado, frente al resto de muertos profanos ${ }^{55}$.

Plutarco se refiere también a los premios en el Hades en un pasaje de la Comparación entre Cimón y Lúculo (1.2). Allí se hace eco de un texto de la República, al que antes nos referimos, en el que se afirma irónicamente que una corona y un estado de embriaguez sempieterna son las recompensas

Jiménez 1991; A. Barigazzi 1994; S.-T. Teodorsson 1994; R. Aguilar 1996a: 290-292; A. Pérez Jiménez 1998; H. G. Ingenkamp 2001: 133-135; A. Pérez Jiménez 2002; I. Gallo 2003-2004: 204-206; A. PÉrez Jiménez 2011.

${ }^{50}$ Sobre la segunda muerte, cf. G. Soury 1942: 196-203; Y. Vernière 1977: 213-214; A. Pérez Jiménez 1993: 10-11; S.-T. Teodorsson 1994: 116-117; A. Pérez Jiménez 1998: 285, 290-294.

${ }^{51}$ Cf. G. Soury 1942: 187-188; R. Aguilar 1981: 54-57.

${ }^{52}$ Cf. R. Aguilar 1981: 69-70; A. PÉrez-Jiménez 2002: 469-478.

${ }^{53}$ Od. 11.539, 24. 3-14; P1. R. 616b, Grg. 523e-524a. En varias laminillas órficas datadas en el s. IV a.C. (Orph. Fr. 487, 5-6; Orph. Fr. 493) el destino final de los iniciados son las praderas de Perséfone, cf. A. Bernabé; A. I. Jiménez San Cristóbal 2008: 174-177. Sobre la pradera en la tradición indoeuropea, cf. M. H. Velasco López 2001.

${ }^{54}$ Cito algunos ejemplos distantes en el tiempo: Pi. O.2.74ss, P1. R. 363c, Ar. fr. 504, 6 K-A, laminilla órfica de Turios (Orph. Fr. 488, 6, s. IV a. C.), Suppl. Hell 980, Verg. Aen. 6.665. cf. A. Bernabé; A. I. Jiménez San Cristóbal 2008: 124.

55 Sobre la coronación de las almas en Plutarco, véase también G. Soury 1942: 189. 
prometidas a los iniciados órficos y dionísiacos ${ }^{56}$. Platón utiliza la metáfora de la borrachera eterna para poner de manifiesto la absurdidad, en su opinión, de prácticas rituales en que el vino, símbolo de Dioniso, tiene vital importancia en vida y tras la muerte. Plutarco con su comentario supo captar perfectamente la ironía del filósofo ateniense: si el iniciado órfico aspira a la comunión con Dioniso, dios del vino, qué mejor manera de lograrla que la embriaguez eterna en un banquete junto al resto de iniciados.

\section{Conclusiones}

Plutarco asume el postulado de que el comportamiento de los hombres en vida condiciona el destino del alma tras la muerte. La conducta puede valorarse atendiendo a criterios morales, jurídicos y racionales o bien de acuerdo con parámetros estrictamente religiosos, como estar iniciado o no. En la pintura escatológica se advierten trazos de raigambre platónica, junto a imágenes tomadas de cultos mistéricos, pero sin que Plutarco renuncie a su propio aporte original, como la legitimidad de los jueces, la topografía lunar-celeste, la clasificación de las almas o las lagunas de metal.

El alma ha de someterse al veredicto de Éaco, Minos y Radamantis, que determinan si han de ser premiadas o condenadas. El dictamen queda garantizado por las virtudes éticas de los propios jueces y por la ecuanimidad que les confiere el hecho de juzgar en el Hades y ser inmunes, por tanto, a intereses crematísticos. Las almas se distinguen fundamentalmente por su tonalidad y por su movimiento. Las condenadas son clasificadas por colores según la gravedad de sus delitos. Divinidades vengadoras las someten a penas diversas para purificarlas, aunque algunas son incurables y quedan aprisionadas para siempre. Otras son sumergidas en lagunas de oro, plomo y hierro, imagen que recuerda los métodos alquímicos recogidos en escritos gnósticos. En la mayoría de los casos el alma tiene un papel pasivo, es decir, es receptora de los castigos y marcas que la identifican como culpable. En general, Plutarco se aleja del lado violento que el castigo tiene en las descripciones platónicas y opta por una visión contundente pero aséptica de las almas condenadas. Sí se hace eco, en cambio, de elementos como la corona y la pradera, que son recurrentes en la imaginería tradicional que describe la bienaventuranza de las almas justas, y que sitúa en la fase inmediatamente anterior al premio supremo que parece ser la disolución de la $\psi u x \eta ́$ en la luna y la llegada del voũ

En definitiva, los mitos que Plutarco idea para exponer su visión de la existencia postmortem logran fusionar perfectamente concepciones escatológicas

${ }^{56}$ P1. R. 363c-d. F. CAsadesús 1999 ha analizado el pasaje platónico y el texto de Plutarco. Véase también A. Bernabé 1996: 67. 
platónicas con elementos procedentes de la propia experiencia iniciática de su autor. La filosofía no cede su espacio, pues se apela constantemente a las virtudes morales y éticas del alma, pero convive con prácticas y creencias religiosas. En este sentido la amalgama plutarquea recuerda la que encontramos en el Papiro de Bolonia, datado en los ss. II/ III d. C., aunque también se ha vinculado con el ambiente judaico del helenismo alejandrino ${ }^{57}$. El papiro refleja la creencia en que tras la muerte del cuerpo el alma es guiada al Hades, donde se la juzga y obtiene un destino en consonancia a su comportamiento en vida. La geografía infernal del papiro y la concepción de un Hades dual con premios y castigos coinciden con la imaginería de los cultos mistéricos. Sin embargo, los condicionamientos éticos requeridos para alcanzar el destino dichoso apuntan a un ideario que desdeña la concepción puramente ritualista. No podemos entrar ahora en el análisis del texto del papiro pero los paralelismos entre la escatología plutarquea y el itinerario infernal, las categorías de almas y los castigos allí descritos merecerían una comparación más detallada.

${ }^{57}$ Editan el texto O.Montevecchi; G. B. Pighi 1947; R. Merkelbach 1951; A. Vogliano 1952; O. Montevecchi 1953: nr. 4; H. Lloyd-Jones; P. J. Parsons 1978 y A. Bernabé 2007, OF 717, con bibliografía. Véanse también los detallados análisis de A. SETAioli 1970, 1972, y 1973. 


\section{Bibliografía}

Adam, H., Plutarchs Schrift non posse suaviter vivi secundum Epicurum. Eine Interpretation, Amsterdam, 1974.

Aguilar, R., La noción del alma personal en Plutarco, Madrid, 1981.

Aguilar, R., "El vuelo del ama”, Fortunatae, 5, 1993: 11-25.

Aguilar, R., Obras morales y de costumbres. Moralia VIII, Madrid, 1996. (1996).

Aguilar, R., "Elementos religiosos en los mitos de Plutarco", in Gallo, I. (ed.), 1996: 285-295. (1996a).

Aguilar, R., "La visión del mundo según las revelaciones. De Sera, 563f-568a

y De genio, 589f-592e", in Frazier, F.; Leão, D. F. (edd.), Tychè et Pronoia. La marche du monde selon Plutarque, Coimbra, 2010: 3-12.

Albini, F., Plutarco. Non posse suaviter vivi secundum Epicurum. Introduzione, Traduzione, Commento, Genova, 1993.

Barigazzi, A., "L'arresto della freccia del tempo (De facie in orbe lunae 941A ss.)", in García Valdés, M. (ed.), 1994: 57-69.

Bernabé, A., "Plutarco e lorfismo", in Gallo, I. (ed.), 1996: 63-104.

Bernabé, A., "Platone e l'orfismo", in Sfameni Gasparro, G. (ed.), Destino e salvezza: tra culti pagani e gnosi cristiana. Itinerari storico-religiosi sulle orme di Ugo Bianchi, Cosenza, 1998: 37-97.

Bernabé, A., "La experiencia iniciática en Plutarco", in Pérez Jiménez, A.; Casadesús, F. (edd.), 2001: 5-22.

Bernabé, A., "Los terrores del más allá en el mundo griego. La respuesta órfica", in Díez de Velasco, F. (ed.), Miedo y religión, Madrid, 2002: 321-329.

Bernabé, A., Poetae Epici Graeci Testimonia et Fragmenta, Pars II Orphicorum et Orphicis similium Testimonia et Fragmenta, Fasciculus 3, Berolini, Novi Eboraci, 2007.

Bernabé, A., Platón y el orfismo. Diálogos entre religión y filosofía, Madrid, 2011.

Bernabé, A., Jiménez San Cristóbal, A. I., Instructions for the Netherworld. The Orphic Gold Tablets, ed. revised and enlarged, Leiden, Boston, Köln, 2008.

Bescond, L., "La doctrine eschatologique dans le mythe du Gorgias", in Dumond, P.; Bescond, L. (edd.), Politique dans l'Antiquite, Lille, 1986: 67-87. 
Boulogne, J., “L'enfer ouranien de Plutarque”, in Thomas, J. (ed.), L’imaginaire religieux gréco-romain, Perpignan, 1994: 217-234.

Boulogne, J., "Les couleurs du ciel ou la réécriture par Plutarque des mythes escathologiques de Platon", Euphrosyne, 27, 1999: 17-29.

Boulogne, J., "Plutarque et l'hermétisme", in Ribeiro Ferreira, J.; Van der Stockt, L.; CÉu Fialho, M. (edd.), Philosophy in Society. Virtues and Values in Plutarch, Leuven, Coimbra, 2008: 53-64.

Brenk, F., In Mist Apparelled. Religious Themes in Plutarch's Moralia and Lives, Leiden, 1977.

Brenk, F., "Demonology in the Early Imperial Period", ANRW II, 16,3. Berlin, New York, 1986: 2068-2145.

Brenk, F., "An Imperial Heritage: The Religious Spirit of Plutarch of Chaironeia", ANRW II, 36, 1, Berlin, New York, 1987: 249-349.

Brenk, F., "The Origin and the Return of the Soul in Plutarch", in García VALDÉs, M. (ed.), 1994: 3-24.

Casade sús, F., "La borrachera eterna como premio. El testimonio de Plutarco", in Montes Cala, J. G.; Sánchez Ortiz de Landaluce, M.; Gallé Cejudo, R. J. (edd.), 1999: 161-170.

Coelho, E., Los jueces infernales en la literatura griega, Tesis doctoral inédita, Universidad Complutense, Madrid, 2007.

Culianu, I. P., Psychanodia. A Survey of the Evidence Concerning the Ascension of the Soul and its Relevance, Leiden, 1983.

Cumont, F., Recherches sur le symbolisme funeraire des Romains, Paris, 1966.

Dalfen, J., "Platons Jenseitsmythen: Eine 'neue Mythologie'?", in Janka, M.; Schafer, C. (edd.), Platon als Mythologe. Neue Interpretationen zu den Mythen in Platons Dialogen, Stuttgart, 2002: 214-230.

Díez de Velasco, F., "Un problema de delimitación conceptual en Historia de las Religiones: la mística griega”, in Plácido, D.; Alvar, J.; Casillas, J. M.; Fornis, C. (edd.), Imágenes de la Polis, Madrid, 1997: 407-422.

Dodns, E. R., Plato. Gorgias. A Revised Text with Introduction and Commentary, Oxford, 1959.

Donini, P., "Science and Metaphysics: Platonism, Aristotelianism, and Stoicism in Plutarch's On the Face in the Moon", in Dillon, J. M.; Long, A. A., The Question of "Eclecticism". Studies in Later Greek Philosophy, Berkeley, 1988: 126-144. 
Durán López, M. A., "El mito del Gorgias en la Consolatio ad Apollonium”, in García Valdés, M. (ed.), 1994: 643-650.

Durán López, M. A., "Una escena báquica en el mito de Tespesio: contenido y función”, in Montes Cala, J. G.; Sánchez Ortiz de Landaluce, M.; Gallé Cejudo, R. J. (edd.), 1999: 211-219.

Durán López, M. A., "Encrucijadas en el mundo místico de Plutarco", in Pérez Jiménez, A.; Casadesús, F. (edd.), 2001: 99-106.

Frazier, F., "Une relecture du mythe final du Phédon. Le philosophe et son logos", in David, S.; GÉny, E. (edd.), Troikka. Parcours antiques. Mélanges offerts à M. Woronoff, vol. I, Presses Univ. de Franche-Comté, 2007: 189201.

Frazier, F., "Quand Plutarque actualise le mythe d'Er. Delphes, la justice e la providence dans le mythe de Thespésios (De Sera 22. 563B-33. 568A)", in Van der Stock, L.; Titchener, F.; Ingenkamp, H. G.; Pérez Jiménez, A. (edd.), Gods, Daimones, Rituals, Myths and History of Religions in Plutarch's Works. Studies Devoted to Professor Frederick E. Brenk by the International Plutarch Society, Málaga, 2010: 145-162.

Gallo, I., "Funzione e significato dei miti nei dialoghi 'morali' di Plutarco", in López Férez, J. A. (ed.), Mitos en la literatura griega helenistica e imperial, Madrid, 2003-2004: 197-208.

Gallo, I., (ed.), Plutarco e la Religione. Atti del VI Convegno plutarcheo, Ravello, 29-31 maggio 1995, Napoli, 1996.

García López, J.; Morales Ortiz, A., Plutarco. Obras morales y de costumbres XIII. Sobre la música (Pseudo Plutarco). Fragmentos, Madrid, 2004.

García VAldés, M., (ed.), Estudios sobre Plutarco: ideas religiosas. Actas del III Simposio Internacional sobre Plutarco, Oviedo, 30 de abril a 2 de mayo de 1992, Madrid, 1994.

Gómez Cardó, P., "Axíoco", in Platón. Diálogos VII. Dudosos. Apócrifos. Cartas, Madrid, 1992: 389-425.

Hamilton, W., “The Myth in Plutarch's De facie (940F-945D)”, CQ, 28, 1934: 24-30. (1934).

Hamilton, W., "The Myth in Plutarch's De genio (589F-592E)”, CQ, 28, 1934: 175-182. (1934a).

Hani, J., "Le mythe de Timarque chez Plutarque et la structure de l'extase", $R E G, 88,1975: 105-120$. 
Hölnes кamp, K. J., Schiedsrichter, Gesetzgeber und Gesetzgebung im archaischen Griechland, Sttutgart, 1999.

Ingen Kamp, H. G., "Juridical and Non-Juridical Eschatologies and Mysteries", in Pérez Jiménez, A.; Casadesús, F. (edd.), 2001: 131-142.

Jiménez San Cristóbal, A. I., "El concepto de dike en el orfismo", in Alvar Ezquerra, A.; Gónzalez Castro, J. F. (edd.), Actas del XI Congreso Español de Estudios Clásicos, Madrid, I, 2005: 351-361.

Jones, R. M., The Platonism of Plutarch, Chicago, 1916.

Lloyd-Jones, H.; Parsons, P. J., "Iterum de Catabasi Orphica", in Kyklos. Festschrift Keydell, Berlin, 1978: 88-108 (= The Academic Papers of Sir. H. Lloyd-Jones, Oxford, 1990, 333-342).

Marcos Montiel, J. F., Plutarco. Obras morales y de costumbres XII. Tratados antiepicúreos, Madrid, 2004.

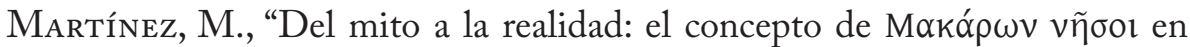
Platón, Aristóteles y Plutarco", in Pérez Jiménez, A.; García López, J.; Aguilar, R. (edd.), 1999: 95-110.

MÉAutis, G., “Le mythe de Timarque”, REA, 1950: 201-211.

Merkelbach, R., "Eine orphische Unterweltsbeschreibung auf Papyrus", $M H, 8,1951: 1-11$.

Montes Cala, J. G.; Sánchez Ortiz de Landaluce, M.; Gallé Cejudo, R. J., (edd.), Plutarco, Dioniso y el vino. Actas del VI Simposio Español sobre Plutarco, Cádiz, 14-16 mayo de 1998, Madrid, 1999.

Montevecchi, O., Papyri Bononienses I, Milano, 1953.

Montevecchi, O.; Pighi, G. B., "Prima ricognizione dei papiri dell'Università di Bologna”, Aegyptus, 27, 1947: 175-183.

Morales Otal, C.; García López, J., Plutarco. Obras morales y de costumbres II, Madrid, 1986.

Pérez Jiménez, A., "Plutarco y el paisaje lunar", in García López, J.; Calderón Dorda, E. (edd.), Estudios sobre Plutarco:paisaje y naturaleza. Actas del II Simposio Español sobre Plutarco, Madrid, 1991: 307-317.

Pérez Jiménez, A., "El viaje sidéreo de las almas”, Fortunatae, 5, 1993: 101123.

Pérez Jiménez, A., "Ciencia, religión y literatura en el mito de Sila de Plutarco", in Brioso, M.; González Ponce, F. J. (edd.), Actitudes literarias en la Grecia romana, Sevilla, 1998: 283-294. 
Pérez Jiménez, A., "Plutarco versus Platón: espacios místicos en el mito de Tespesio”, in Pérez Jiménez, A.; Casadesús, F. (edd.), 2001: 201-210.

Pérez Jiménez, A., "Valores literarios del mito de Sila: anotaciones estilísticas a la antropología de Plu. De facie 943a-943b”, in Torraca, L. (ed.), Scritti in onore di Italo Gallo, Napoli, 2002: 463-478.

Pérez Jiménez, A., "En las redes de xpóvoc. La peregrinación inicial de las almas contaminadas", in Herrero de JÁuregui, M.; Jiménez San Cristóbal, A. I.; Luján Martínez, E. R.; Martín Hernández, R.; Santamaría Álvarez, M. A.; Torallas Tovar, S., Tracing Orpheus, Berlin, Boston, 2011: 205-211.

Pérez Jiménez, A.; Casadesús, F., (edd.), Estudios sobre Plutarco: misticismo y religiones mistéricas en la obra de Plutarco. Actas del VII Simposio español sobre Plutarco, Palma de de Mallorca, 2-4 de noviembre de 2000, Madrid, Málaga, 2001.

Pérez Jiménez, A.; García López, J.; Aguilar, R., (edd.), Plutarco, Platón y Aristóteles. Actas del V Congreso Internacional de la I. P. S., MadridCuenca, 4-7 de mayo de 1999, Madrid, 1999.

Richardson, H., "The Myth of Er (Plato, Republic 616b)", CQ, 20, 1926: $115-131$.

Roskam, R., "Le pari de Plutarque'. Computing pros and cons in the face of death”, in Pérez Jiménez, A.; García López, J.; Aguilar, R. (edd.), 1999: 463-474.

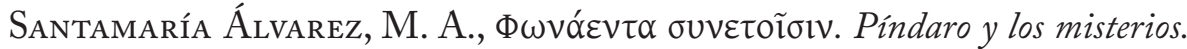
Edición y comentario de la Olimpica segunda, Tesis doctoral inédita, Salamanca, 2003.

Santamaría Álvarez, M. A., "El motivo literario del viaje al Hades en el mito de Tespesio (Ser. num. vind. 563C-568A)”, in Nieto Ibáñez, J.M.; López López, R. (edd.), El amor en Plutarco. IX Simposio Internacional de la Sociedad Española de Plutarquistas, León, 28-30 de septiembre de 2006, León, 2007: 877-887.

Sedley, D., "Myth, punishment and politics in the Gorgias", in Partenie, C. (ed.), Plato's Myths, Cambridge, New York, 2009: 51-76.

Setaioli, A., "Nuove osservazioni sulla 'descrizione dell'oltretomba' nel papiro di Bologna”, SIFC, 42, 1970: 179-224.

Setaioli, A., "L'imagine delle bilance e il giudizio dei morti", SIFC, 44, 1972: $38-54$. 
Setaioli, A., "Ancora a proposito del papiro bolognese n. 4", SIFC, 45, 1973: 124-133.

Sirinelli, J., Plutarque de Chéronée. Un philosophe dans le siècle, Paris, 2000.

Sourvinou-Inwood, C., 'Reading' Greek Death. To the End of the Classical Period, Oxford, 1999.

Soury, G., La démonologie de Plutarque. Essai sur les idées réligieuses et les mythes d'un Platonicien éclectique, Paris, 1942.

Taufer, M., "Er e Tespesio. Plutarco interprete di Plutarco", Lexis, 17, 1999: 303-318.

Taufer, M., Il mito di Tespesio nel De sera numinis vindicta di Plutarco, Napoli, 2010 (non vidi).

Teodorsson, S.-T., "The Psychology of De facie and De virtute morali", in García Valdés, M. (ed.), 1994: 115-122.

Velasco López, M. H., El paisaje del Más Allá. El tema del prado verde en la escatología indoeuropea, Valladolid, 2001.

Vernière, Y., "Le Léthé de Plutarque”, REA, 66, 1964: 22-32.

Vernière, Y., Symboles et mythes dans la pensée de Plutarque. Essai d'interprétation philosophique et religieuse des Moralia, Paris, 1977.

Vernière, Y., "Initiation et eschatologie chez Plutarque”, in Ries, J. (ed.), Les rites d'initiation, Louvain-La-Neuve, 1986: 335-352.

Vogliano, A., "Il papiro bolognese Nr. 3", Acme, 5, 1952: 385-417.

Wiener, C., "Kurskorrektur auf der Jenseitsfahrt. Plutarchs ThespesiosMythos und Kolotes' Kritik an Platons Politeia", WJA, 28, 2004: 49-63. 